\title{
Receptor Activation and Homer Differentially Control the Lateral Mobility of Metabotropic Glutamate Receptor 5 in the Neuronal Membrane
}

\author{
Arnauld Sergé, Lawrence Fourgeaud, Agnès Hémar, and Daniel Choquet \\ Physiologie Cellulaire de la Synapse, Centre National de la Recherche Scientifique, Unité Mixte de Recherche 5091, \\ Institut François Magendie, 33077 Bordeaux, France
}

Glutamate receptors are clustered at the membrane through interactions with intracellular scaffolding proteins and cytoskeletal elements but can also be found in intracellular compartments or dispersed in the membrane. This distribution results from an equilibrium between the different pools of receptors whose dynamic is poorly known. The group I metabotropic glutamate receptor 5 (mGluR5) is concentrated in an annulus around the postsynaptic density but also found in large amounts in the extrasynaptic membrane. To analyze the dynamic of stabilization of mGluR5, we used single-particle tracking, force measurements, and fluorescence recovery to measure the mobility of mGluR5. We found that receptor activation increases receptor diffusion, whereas the scaffolding protein
Homer favors confinement of receptor movements within clusters of Homer-mGluR5. However, this stabilization is reversible, because even in the presence of Homer, receptors still enter and exit from clusters at fast rates. Furthermore, clusters themselves are highly dynamic both in their movements and in their composition, which can vary within tens of seconds. Thus, exchange of receptors between dispersed and clustered states is fast and regulated during physiological processes. These properties may explain certain fast changes in receptor composition observed at postsynaptic densities.

Key words: mGluR5; single particle tracking; FRAP; diffusion; DHPG; Homer; receptor clustering
Stabilization of neurotransmitter receptors by interactions with cytosolic proteins and cytoskeletal elements is necessary for receptors to remain localized at given sites. Indeed, receptors not bound to a rigid structure diff use over large distances (Saxton and Jacobson, 1997). Reversible stabilization of neurotransmitter receptors participates in the formation and plasticity of synapses. During synaptogenesis, receptors evolve from a dispersed and diffusive state in the plasma membrane to an immobilized and concentrated state at synaptic sites through binding to intracellular partners by a diffusion-trap mechanism, a process best studied at the neuromuscular junction (Salpeter and Loring, 1985). We have shown that stabilization of the inhibitory glycine receptor by the scaffolding protein gephyrin is highly dynamic (Meier et al., 2001), because glycine receptors frequently alternate between stabilized and unstabilized states. At excitatory synapses, variations in receptor numbers participate in activitydependent plasticity of synaptic transmission (Scannevin and Huganir, 2000; Carroll et al., 2001), but direct measurement of receptor mobility was not reported.

Group I metabotropic glutamate receptors (mGluR1/5) are localized to an annulus large of $60 \mathrm{~nm}$ surrounding the postsyn-

\footnotetext{
Received Aug. 27, 2001; revised Jan. 22, 2002; accepted Feb. 12, 2002.

This work was supported by grants from the Centre National de la Recherche Scientifique, the Fondation pour la Recherche Médicale, the Association Française contre les Myopathies, and the council of the Région Aquitaine. We thank J. P. Pin and P. Worley for the gifts of mGluR5 and Homer cDNAs, P. Worley for the gift of pan anti-Homer antibody, C. Mulle, D. P. Felsenfeld, and A. Borgdorff for critical reading of this manuscript, F. Coussen for assistance in molecular biology, and F. Rossignol and P. Gonzales for cell cultures.

Correspondence should be addressed to Daniel Choquet, Physiologie Cellulaire de la Synapse, Centre National de la Recherche Scientifique, Unité Mixte de Recherche 5091, Institut Magendie, rue Camille Saint Saëns, 33077 Bordeaux Cedex, France. E-mail: dchoquet@u-bordeaux2.fr.

Copyright (C) 2002 Society for Neuroscience $0270-6474 / 02 / 223910-11 \$ 15.00 / 0$
}

aptic density (PSD) of glutamatergic synapses (Baude et al., 1993; Nusser et al., 1994; Vidnyánszky et al., 1994). This localization is not stringent, because up to $75 \%$ of mGluR1/5 are found at nonsynaptic sites (Lujan et al., 1997). Concentration of mGluR1/5 at synaptic sites likely results from an equilibrium between synaptic and extrasynaptic receptors through low-affinity binding to partners in the PSD such as Homer or Shank (Brakeman et al., 1997; Sun et al., 1998; Naisbitt et al., 1999). Homer protein variants contain an Ena/vasodilator-stimulated phosphoprotein homology $1(\mathrm{EVH}-1)$ domain that interacts with a prolinrich sequence on the $\mathrm{C}$ terminus of mGluR1/5 (Xiao, 1998). Most variants also have a coiled-coil domain at their $\mathrm{C}$ termini that allows them to form multimers (Xiao, 1998; Shiraishi et al., 1999). Homers may serve as anchoring partners for mGluRs at synaptic sites, because both colocalize at the light microscopy level (Tadokoro et al., 1999), and long forms of Homer are able to cluster mGluR1/5 (Tadokoro et al., 1999; Ciruela et al., 2000). However, Homer is evenly distributed over the PSD (Xiao, 1998), whereas mGluRs are perisynaptic. Alternatively, Homer could be involved in regulation of mGluR signaling ( Tu, 1998; Ango et al., 2001) or intracellular trafficking (Roche et al., 1999; Ango et al., 2000; Ciruela et al., 2000). On long terms, upregulation of the expression of the monovalent short Homerla could modulate mGluR localization and function by antagonizing binding of other members of the Homer family (Tu, 1998; Xiao, 1998; Roche et al., 1999; Tadokoro et al., 1999). On short terms, the synaptic localization of Homer is regulated within minutes by calcium influx through NMDA receptors (Okabe et al., 2001).

The spatial distribution of mGluRs at equilibrium will strictly depend both on the affinity of the association between the receptors and their partners and on the effect of this association on the mobility of the receptors. We determined by single-particle track- 
ing in real time the parameters of the mobility of resting and activated mGluR5 in the presence or absence of an interaction with a cytoplasmic partner.

\section{MATERIALS AND METHODS}

Cultures. Ptk2 cells were grown in DMEM without phenol red and with

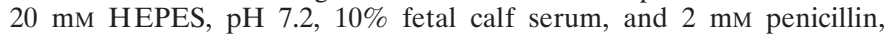
streptomycin, and glutamax at $37^{\circ} \mathrm{C}$ and $5 \% \mathrm{CO}_{2}$. Hippocampal neurons were obtained from embryonic day 18 rat embryos, and cultured as described (Hemar et al., 1997). All cells were grown on glass coverslips. All reagents were from Invitrogen (Cergy-Pontoise, France).

Constructs. The epitope-tagged mGluR5a expression plasmids were constructed using, as a template, the pRKG5a plasmid kindly provided by J. P. Pin (Centre National de la Recherche Scientifique, Unité Propre de Recherche 9023, Montpelier, France) (rat mGluR5a cDNA into the expression plasmid pRK5; Joly et al., 1995). An MluI restriction site was inserted just after the signal peptide for the N-terminal epitope-tagged receptor (between the Ser-22 and Ser-23 codons of mGluR5a, amino acid 1 being the initiating methionine) or just before the stop codon for the C-terminal epitope-tagged receptor, using a PCR overlap extension method. Sense and antisense oligonucleotides coding the c-myc epitope (TREQKLISEEDLAR) with $M l u$ I cohesive ends were synthesized and used to introduce the c-myc into the N-terminal MluI site (mGluR5-myc). A green fluorescent protein (GFP) coding fragment with $M l u$ I cohesive ends was obtained by PCR on the pEGFP-N1 plasmid using the 5' oligonucleotide acgcgtGTGAGCAAGGGCGAGGAGCTGTTC and the $3^{\prime}$ oligonucleotide acgegtCTTGTACAGCTCGTCCATGCCGAG. This fragment was then introduced into the C-terminal MluI site (mGluR5-GFP). The construct expressing mGluR5a with a myc tag at the $\mathrm{N}$ terminus and the GFP at the $\mathrm{C}$ terminus was done by ligation of the 6514 bp NheI-Pst I fragment of mGluR5-myc and the 2608 bp NheI-Pst I fragment of mGluR5-GFP (mGluR5-myc-GFP). The mGluR5-myc receptor was expressed in Ptk2 cells. It is functional in these cells, because application of glutamate to transfected cells elicited oscillations in intracellular calcium levels indistinguishable from those triggered through wild-type receptors (data not shown). The mGluR5a cytoplasmic deletion mutant, mGluR5-delC-myc (N887stop) was provided by J. P. Pin (Mary et al., 1998). cDNAs corresponding to Homer1b were synthesized from mouse brain total RNAs and reverse-transcribed with avian myeloblastosis virus RNA polymerase using the reverse primer 5'-GGATCCGCGCTGCATTCC-AGTAGCTTGGC-3' containing a BamHI site and corresponding to the end of rat Homer1b. The PCR reaction was done with a 5' primer, 5'-AAGCTTCGATCATGGGGGAGCAACCTATCTTC-3', containing a HindII site and the oligonucleotide 5'GGATCCGCGCTGCATT-CCAGTAGCTTGGC-3'. The product of the PCR reaction was subcloned on pGEM-T vector from Promega (Charbonnieres, France) following a standard protocol and sequenced. The corresponding Homer1b cDNA was fused to the GFP cDNA by subcloning in pEGFP-N1 (BD Biosciences, Le Pont de Claix, France) cut by HindII-Bam HI, leading to insertion of GFP on the C terminus of Homer1b. Homer1a was obtained by PCR reaction on the Homer1b matrix with the $5^{\prime}$ oligonucleotide 5'-AAGCTTCGATCATGGGGGAGCAACCTATCTTC-3' anda3' primer,5'-GGATCCGCCTTAATCATGATTGCTGAATTGAATGTGTACCT-3', containing the HindII restriction site. Homer1a was then sequenced and subcloned in pEGFP-N1 vector following the same protocol as for Homer1b. The primary structure of the various constructs was verified by DNA sequencing. In some experiments, myc-tagged Homer1b provided by P. Worley (Johns Hopkins School of Medicine, Baltimore, MD) and hemagglutinin (HA)tagged mGluR5a were used instead of Homer1b-GFP and mGluR5amyc, leading to identical results.

Transient transfection procedures. Ptk2 cell transfections were performed in subconfluent $(60-70 \%)$ cultures using Fugen (Roche Diagnostics, Meylan, France). Neurons were transfected 2-7 d after plating using Effecten (Qiagen, Courtaboeuf, France). Both protocols were performed following the manufacturers' indications. Transient expression was allowed for $24-48 \mathrm{hr}$ at $37^{\circ} \mathrm{C}$ and $5 \% \mathrm{CO}_{2}$.

Immunocytochemistry. Cells were incubated $15 \mathrm{~min}$ with the 9E10 mouse anti-myc antibody (Roche Diagnostics) at $20^{\circ} \mathrm{C}$ and then fixed with $4 \%$ paraformaldehyde and sucrose, washed with PBS and BSA, and revealed with $\mathrm{Cy} 3$-coupled anti-mouse secondary antibodies (Jackson ImmunoResearch, West Grove, PA). Staining was also performed on occasions on live cells at $4^{\circ} \mathrm{C}$ to fully inhibit endocytosis or after fixation without permeabilization to prevent cross-linking of the receptors by the antibodies as could occur on live cells. Comparable results were obtained in all conditions. Images were acquired using a Quantix digital cooled CCD camera (Photometrix, Paris, France), and fluorescence levels were measured using Metamorph (Universal imaging, Downingtown, PA) Briefly, for each cell, clusters were detected using a threshold level set at twice the average fluorescence level measured on the whole-cell surface. The percentage of fluorescence in clusters was calculated relative to the whole-cell fluorescence. The relative receptor density, $R$, was calculated as follows. Areas with a fluorescence level above the average total cell fluorescence were detected by thresholding. This ensured that $\sim 50 \%$ of the receptors were taken into account for this parameter. The percentage of fluorescence in these areas relative to the total cell fluorescence was divided by the percentage of surface occupied by these areas relative to the total cell surface.

Immunoblots. For hippocampus lysate preparation, dissected hippocampi from Wistar rats (4-8 weeks) were homogenized on ice using 15 strokes of a Teflon-glass Elvehjem tissue grinder (Kontes) in homogenization buffer containing $25 \mathrm{~mm}$ HEPES, $\mathrm{pH} 7.4,150 \mathrm{~mm} \mathrm{NaCl}$, and a mix of protease inhibitors (in $\mu \mathrm{g} / \mathrm{ml}: 10$ pepstatin, 10 leupeptin, 10 aprotinin, and 20 Pefabloc). For two hippocampi, homogenization was done in $750 \mu \mathrm{l}$ of homogenization buffer. The homogenate was solubilized by mixing in a 1:1 ratio with the solubilization buffer (homogenization buffer plus $2 \%$ Triton X-100). After $20 \mathrm{~min}$ on ice, the lysate was cleared at $8000 \times g$ for 10 min. For cultured lysates, Ptk 2 cells transfected or not and hippocampal neurons in culture were washed one time in PBS, incubated $10 \mathrm{~min}$ on ice in lysis buffer (25 mM HEPES, pH 7.4, $150 \mathrm{~mm}$ $\mathrm{NaCl}, 1 \%$ Triton $\mathrm{X}-100$, and a mix of protease inhibitors), and then scraped from the dish. The lysates were cleared at $8000 \times g$ for $10 \mathrm{~min}$. For immunoblots, protein concentration of cleared total lysates was measured by bicinchoninic acid assay according to the manufacturer using BSA as a standard (Pierce, Rockford, IL). Forty micrograms of each lysate were run on $7.5 \%$ SDS-PAGE and transferred on an Immobilon-P polyvinylidene difluoride membrane (Millipore, Bedford, MA). The blot was probed first with anti-Vesl-1L (Homer1b) antibody $(0.25 \mu \mathrm{g} / \mathrm{ml}$; Transduction Laboratories, Lexington, KY; catalog \#V10720) and, after deblotting, reprobed with anti-mGluR5 antibody (0.8 $\mu \mathrm{g} / \mathrm{ml}$; Upstate Biotechnology, Lake Placid, NY; catalog \#06-451).

Video microscopy and optical trapping. Experiments and data analysis were performed essentially as described previously (Meier et al., 2001). Briefly, cultured cells were mounted in culture medium in a chamber between two coverslips. The chamber was installed on an IX-70 inverted microscope (Olympus, Bordeaux, France) heated at $37^{\circ} \mathrm{C}$ with an air blower (WPI, Slovenage, UK). Cells were visualized under red illumination and differential interference contrast (DIC) through a $100 \times$ Plan-apo objective on a C2400 camera (Hamamatsu, Paris, France). An optical trap was formed in the plane of focus with the beam of a Ti-sapphire laser (Spectra-Physics, Les Ulis, France) tuned at $800 \mathrm{~nm}$ and $200 \mathrm{~mW}$. Latex beads $0.5 \mu \mathrm{m}$ in diameter (Polysciences, Eppelheim, Germany) coated with anti-myc antibodies were manipulated with the optical trap and maintained in contact with the surface of the transfected cells $(5 \mathrm{sec})$ to allow their attachment to the myc-tagged receptors. On release of the trap, beads remaining in the plane of focus were scored as attached, and video images were recorded on a videocassette recorder for later analysis. Forty-six percent and $14 \%$ of the beads attached to transfected and untransfected cells, respectively, indicating the good specificity of binding. Transfected cells were identified under epifluorescence by the green fluorescence of GFP or GFP-tagged Homer cotransfected with the myc-tagged subunits. Fluorescence images were acquired at a 2 or $5 \mathrm{sec}$ frame rate with a Pentamax camera (Princeton Instruments Inc., Evry, France) and in parallel with the DIC images. For agonist application and wash, the $100 \mu \mathrm{l}$ chamber was perfused with $500 \mu \mathrm{l}$ of medium containing or not a $10 \mu \mathrm{M}$ concentration of the specific agonist of group I mGluRs $S$-(3,5)-dihydroxy-phenyl-glycine (DHPG; FisherBioblock, Illkirch, France).

Bead tracking and data analysis. Video images were digitized at $25 \mathrm{~Hz}$ with a digital video recorder (Imasys, Paris, France), and bead positions were followed using homemade software (Choquet et al., 1997) with an accuracy of 5-10 nm. For each recording, stretches of confined and diff usive periods were isolated using the associated $L$ function (Saxton, 1995; Simson et al., 1995; Meier et al., 2001). Confinement is defined as periods in which a protein remains in a membrane subregion for a duration longer than a Brownian diffusant would stay in an equally sized region. The probability $\psi$ that a given protein with diff usion coefficient $D$ will stay in a region of radius $R$ for time $t$ was calculated (Saxton, 1995; Simson et al., 1995) to be $\log (\psi)=0.2048-2.5117 D t / R^{2}$. We took $D=$ 
$2.5 \times 10^{-2} \mu \mathrm{m}^{2} / \mathrm{sec}$, which is the average value we measured from mean squared displacement (MSD) curves of trajectories of mGluR5-delCmyc coupled beads, which are mostly Brownian diffusant. Every point in a trajectory is taken as starting point for a series of segments ranging in size from 4 to 144 frames. For each of these segments, the point with the largest displacement from the starting point determines the value of $R$ for that segment. The $L$ function is then derived from $\psi$ by $L=-\log (\psi)-$ 1 if $\psi \leq 0.1$ and $L=0$ if $\psi>0.1$ (this thresholding ensures that if a segment has a likelihood $\geq 10 \%$ to be of random origin, it is assigned $L=0$ ). For every point within a trajectory, $L$ is averaged over all segments containing that specific point. We use this averaged $L$ as a confinement index. High values of $L$ denote periods in which the particle is confined to a region longer than a random diffusant would remain. A stretch of trajectory was detected as confined if its $L$ function remained at $>3.16$ for $>2.5 \mathrm{sec}$. These values ensured a likelihood of $99.3 \%$ to arise from a confined behavior. Short stretches $(<2.5 \mathrm{sec})$ of trajectories with a confinement index higher than the defined threshold were not retained as being confined, because they could arise from random movements of a freely diffusing particle. Reciprocally, short stretches of trajectories with a low confinement index are certain to occur from a diffusive particle.

For each stretch of $N(x, y)$ positions, the MSD function at time $n . d t$ was computed as:

$$
\operatorname{MSD}(n . d t)=\frac{\sum_{i=1}^{i=N-n}\left(x_{i+n}-x_{i}\right)^{2}+\left(y_{i+n}-y_{i}\right)^{2}}{(N-n)} d t,
$$

where $d t$ is the sampling time interval (40 msec), and $x_{\mathrm{i}}$ and $y_{\mathrm{i}}$ are the $x$ and $y$ coordinates of the bead position at time $i . d t$. These MSD plots were fitted by the function:

$$
\operatorname{MSD}(t)=2 R^{2}\left(1-e^{-2\left(D_{\text {inst }}-D_{\text {asympt }}\right) t / R^{2}}\right)+4 D_{\text {asympt }} t,
$$

where $D_{\text {inst }}$ is the diff usion coefficient inside the confining subdomain, $R$ is the radius of the domain, and $D_{\text {asympt }}$ is the diffusion coefficient of the domain.

Measure of dragging forces. Beads bound to mGluR5-myc at the surface of Ptk2 cells coexpressing Homer1b-GFP were trapped by the laser tweezers set at different powers. The stage was then moved laterally at a constant speed $(v=8 \mu \mathrm{m} / \mathrm{sec})$ to try to drag the bead within the plane of the membrane. The minimum force required to drag the bead over $>2$ $\mu \mathrm{m}$ was determined by repeating this procedure at increasing laser powers. The spring constant of the laser tweezers was determined by measuring the deviation of the position of a trapped bead relative to the center of the trap in an uniform flow produced by moving the stage laterally at constant speed. The fluid applied on the bead a force that could be calculated according to Stoke's law: $F=6 \pi \eta R v$, where $\eta$ is the viscosity of the fluid, $R$ is the radius of the bead, and $v$ is the speed of the flow.

Fluorescence recovery after photobleaching. Hippocampal neurons cultured 5-9 d in vitro (DIV) and cotransfected with mGluR5-GFP and Homer1b-myc were mounted in a recording chamber at $37^{\circ} \mathrm{C}$ as for optical trapping. GFP fluorescence was monitored through a $100 \times$ UplanFl objective and imaged on an intensified video-charged coupled device camera (Princeton Instruments). Fluorescence was excited either full-field with an argon lamp filtered between 470 and $490 \mathrm{~nm}$ or locally with the $488 \mathrm{~nm}$ line of the focused Gaussian beam of a 177-GO2 argon laser (Spectra-Physics). At the object focal plane, the beam had a diameter of $2.1 \mu \mathrm{m}$. The laser power was modulated using a Mascot 8421 acousto-optic modulator (Crystal Technology Inc., Palo Alto, CA) placed in the optic path before the microscope. The full-field image was first used to position the laser beam on a neurite, allowing for choosing for regions with scattered or clustered receptors. A region was considered containing clustered receptors if its fluorescence intensity was three times that of an adjacent region of the same size. For fluorescence recovery after photobleaching (FRAP) recordings, full-field excitation was turned off, and fluorescence intensity was excited by the laser beam continuously monitored with the laser set at $8 \mu \mathrm{W}$. To photobleach the sample, laser power was set at $5 \mathrm{~mW}$ for $2 \mathrm{sec}$. Fluorescence recovery after photobleaching was fit with an exponential in Kaleidagraph to obtain the half-recovery time and the asymptotic final recovery. The corresponding diffusion coefficient and percentage of fluorescence recovery were calculated as by Axelrod et al. (1976). A region was defined as containing scattered receptors if its average intensity was approximately equal to that of the surrounding cell domain.

\section{RESULTS \\ Movement of mGluR5 studied by single-particle tracking}

We analyzed the mobility of the mGluR5a splice variant tagged at its extracellular $\mathrm{N}$ terminus with the myc epitope (mGluR5-myc) and expressed by transfection in 3-8 DIV hippocampal neurons. To follow receptor movement on the cell surface, we used 0.5$\mu \mathrm{m}$-diameter beads coated with anti-myc antibodies that couple to the myc-tagged receptors. Beads were held $5 \mathrm{sec}$ in contact with live transfected cells using laser tweezers (Fig. $1 A$ ). On release of the tweezers, beads that remained in the plane of focus were scored as attached to the cell, and their movement was tracked by video microscopy in real time (Fig. $1 B$ ). Single-particle tracking has been used in many instances to follow the movement of various types of transmembrane proteins in the plane of the plasma membrane. Both theoretical and experimental data have supported the counterintuitive notion that for particles with a diameter $<1 \mu \mathrm{m}$, diffusion of particle-bound receptors is similar to that of individual receptors (Saffman, 1976; Kucik et al., 1999). Thus, although a variable number of receptors can be bound to each individual bead, their diff usion is only slightly dependent on this number. This was verified in our system, because varying by a factor of 20 the amount of anti-myc antibody associated with the beads did not significantly change the measured diffusion coefficients, although it decreased the fraction of beads that efficiently coupled to transfected cells (Fig. 1C).

When observed for several minutes, beads coupled to mGluR5myc moved on the cell surface over areas only limited by the cell topology. A qualitative analysis of bead trajectories indicates that bead movement is not homogeneous over time but alternates abruptly between periods of fast and slow diffusion. These zones of slow diffusion seemed to be distributed more or less randomly on the cell surface. The variability in movement is most apparent on plots of the diff usion coefficient versus time of the trajectories, which show that diff usion varies over several orders of magnitude within seconds (Fig. 1D). The average of 36 such traces shows that bead-coupled receptors diffuse overall slightly slower over the recording time, being divided by 2 over $200 \mathrm{sec}$ (Fig. $1 F$ ). This is likely to be attributable to the fact that when beads are initially put in contact with cells, they have a higher probability of binding to highly mobile than to slowly mobile receptors, because the former explore larger surface areas per unit time. As beadcoupled receptors move around, they can then encounter sites of binding that will reduce their diffusion. The reduction of the diffusion with time is unlikely to be attributable to cross-linking of the bead with new receptors, because we found little dependence of diffusion over ligand density on the bead, as expected (Saffman, 1976; Kucik et al., 1999). Abrupt bead stopping might be attributable on occasions to sudden recruitment of a new immobile receptor. In contrast, resuming fast movement is unlikely to occur from unbinding of receptors from the bead, because these links have off times in the order of hours. Altogether, this shows that strong variations in receptor diffusion cannot be attributed to increased cross-linking of receptors under the bead over time.

To quantify and precisely detect the transitions between periods of slow and fast diffusion, we used a mathematical function, termed $L$ function or confinement index, which gives an index of the probability that a given time point belongs to a period of 
A
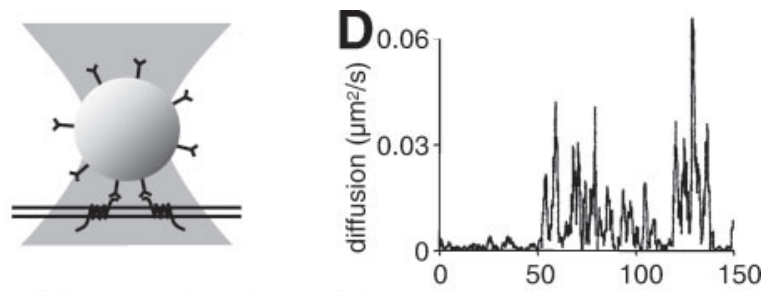

B
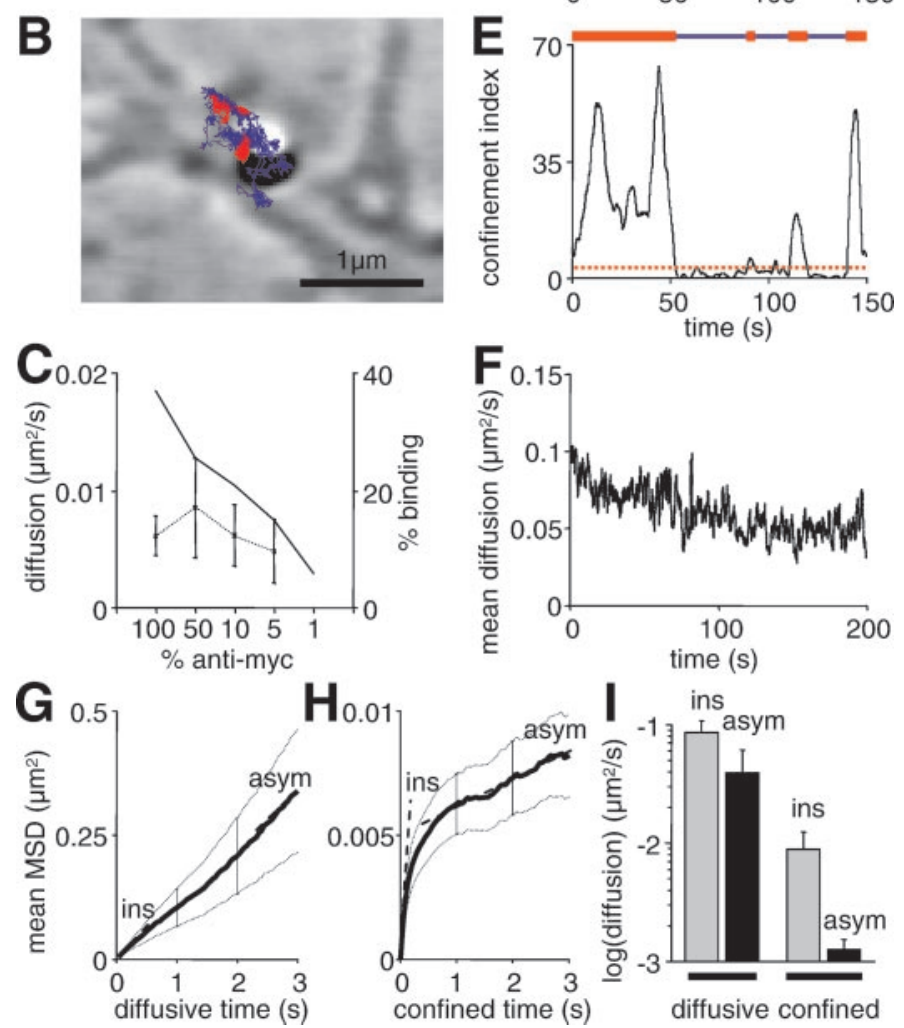

Figure 1. mGluR5 alternates between states of fast and slow diff usion. $A$, Principle of single-particle tracking. A $0.5 \mu \mathrm{m}$ latex bead coated with anti-myc antibodies is manipulated with laser tweezers and held in contact with a live cell transfected with mGluR5-myc or mGluR5-myc-GFP. Contact is maintained $5 \mathrm{sec}$ to allow antibody-receptor interactions. On release of the tweezers, the movement of the bead, and thus of the underlying receptors, is followed in real time by video microscopy. $B$, Typical trajectory of a bead coupled to mGluR5-myc expressed in a neuron at 7 DIV. The movement alternates between fast (blue) and slow (red) diffusion as detected from the curve in $D$. The trajectory is superimposed on the DIC image of the neurite. $C$, Dual plot of the percentage of bead binding to cells (solid line) and the mean diffusion coefficient (dashed line) for mGluR5-bound beads at different dilutions of the antimyc antibody coupled to the bead. The anti-myc antibody was diluted with an anti-HA antibody. Data \pm SEM are given in this and subsequent figures; $6-36$ beads per data point. At $1 \%$ dilution, bead binding is within background nonspecific binding levels; thus diffusion was not computed. $D$, Plot of the diff usion coefficient versus time, calculated for the trajectory in $B$, exhibiting periods of slow and fast diffusion. $E$, Plot of the confinement index versus time, evaluated by the $L$ function, calculated for the same trajectory. Confined events characterized by an $L>3.16$ are indicated above the plot by red boxes and correspond to the red stretches in $B$. This convention is kept throughout the figures. $F$, Plot of the mean diffusion coefficient versus time ( $n=36$ trajectories). $G, H$, Plots of the mean of the MSD functions versus time calculated on diff usive $(G ; n=$ $106)$ and confined $(H ; n=104)$ events. Error bars indicate SEM. Note that MSD curves are almost linear on diffusive events and negatively curved on confined events. I, Histogram of mean instantaneous (ins) and asymptotic (asym) diffusion coefficients, calculated from the slope at the origin or the end of each MSD curve. Values are of the same order of magnitude for diffuse events and differ by one order of magnitude for confined events. reduced diffusion (Saxton, 1995; Simson et al., 1995; Meier et al., 2001). Stretches of slow diffusion (Fig. 1B, red) were detected using a fixed threshold and minimum persistence time for $L$, as exemplified in Figure $1 E$ for a trajectory recorded on a neuron expressing mGluR5-myc. Comparison of the plots of diffusion and $L$ function versus time (Fig. $1 D, E$, respectively) shows that the $L$ function effectively detects periods of low diffusion. This detection allowed for the measurement of the dwell times spent in each state (for example, see Fig. 6).

To further characterize the type of movement within each stretch of trajectory, we calculated the MSD for each identified period. This function is linear with time for a particle undergoing unrestricted Brownian diffusion, the slope of the curve being four times its diffusion coefficient $D$. A deviation from linearity indicates anomalous diffusion. During periods of fast diffusion, the MSD plot is linear (Fig. $1 G$ ), indicating free Brownian diff usion of the underlying receptors. The MSD functions during periods of slow diffusion are drastically different from those during fast diffusion in two aspects (Fig. $1 H$ ). First, the amplitudes of the MSDs are much lower (100 times on average), confirming that the underlying episodes correspond to periods of low diffusion. Second, their shapes are negatively curved, indicating confined diffusion, attributable for instance to confinement of movement by barriers (Saxton, 1995). This was quantified by measuring the slopes of the MSD curves at the origin and at the asymptote, which measure the instantaneous and long-range diffusion coefficients of the receptors, respectively (Fig. 1I). The mean instantaneous and long-range diffusion coefficients during episodes of fast diff usion were similar and on the order of $5 \times 10^{-2} \mu \mathrm{m}^{2} / \mathrm{sec}$. These values are compatible with previously published diffusion coefficients of receptors undergoing free unrestricted Brownian diffusion (Kusumi et al., 1993; Sako and Kusumi, 1995; Choquet et al., 1997; Saxton and Jacobson, 1997). In contrast, during periods of restricted diffusion, the long-range, asymptotic diffusion coefficient was on average 10 times slower than the instantaneous one. This long-range diffusion coefficient was, however, quite variable, because it ranged from 0 to $10^{-2} \mu \mathrm{m}^{2} / \mathrm{sec}$. Altogether, these data show that in neurons, mGluR5-myc alternates between states bearing very different diffusional properties. We next investigated whether the membrane dynamics of the receptor could be regulated by its physiological state or by interaction with intracellular partners.

\section{mGluR5 diffusion is increased by DHPG}

To investigate whether the mGluR5 dynamics in the plasma membrane was regulated by its activity, we performed experiments in the presence or absence of $10 \mu \mathrm{M}$ DHPG, a specific agonist of group I mGluRs. We first verified by calcium imaging that calcium release was triggered by perfusion with $10 \mu \mathrm{M}$ DHPG in neurons transfected with mGluR5-myc (data not shown). Single-particle tracking (SPT) experiments revealed that in the presence of DHPG, mGluR5 diffusion is increased by a factor of 3 (Fig. 2; $p<0.05$ ) during both diffusive and confined events. Moreover, the confinement index during confined events is lower in the presence of DHPG (Fig. 2C,D; mean values \pm SEM, $L=26 \pm 4$ and $17 \pm 4$ in the absence or presence of DHPG, respectively; $p<0.05$ ). In contrast, DHPG does not significantly modify the relative distribution of the diff usive and confined states (Fig. 2E).

\section{Full-length Homer induces aggregation of mGluR5}

We analyzed the effect of Homer1a and Homer1b on the distribution and mobility of mGluR5-myc using transfection of cDNAs 

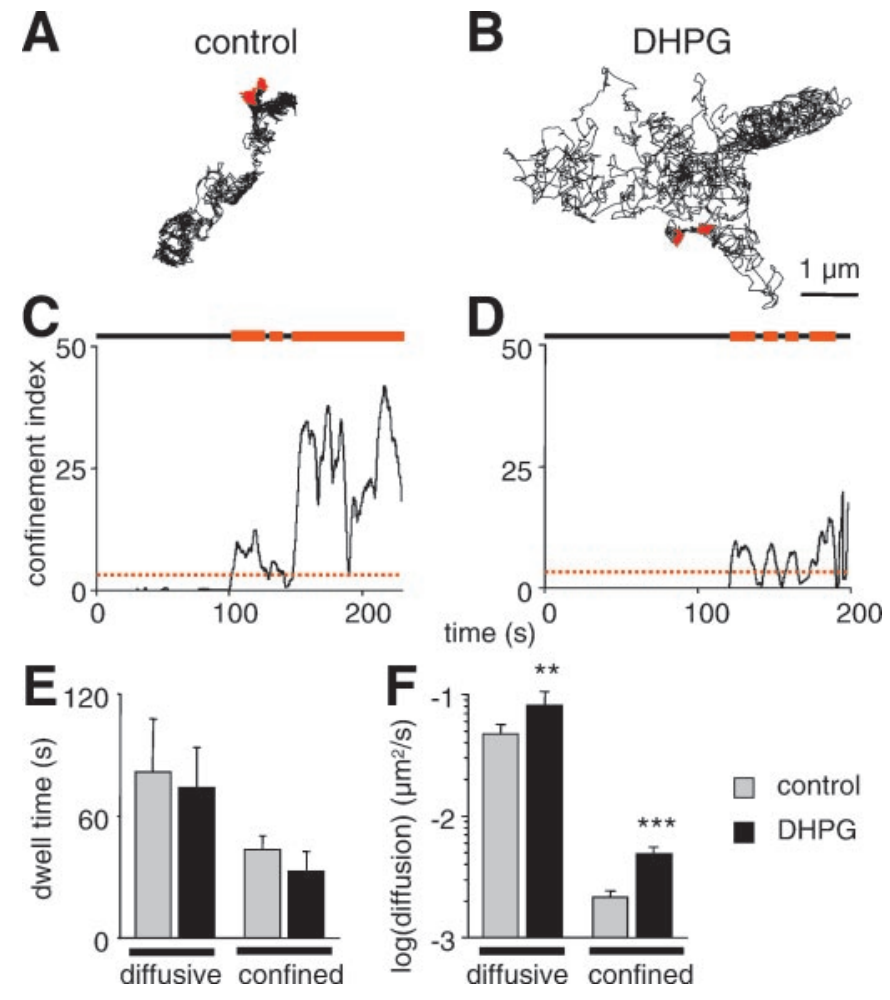

Figure 2. DHPG increases mGluR5 diffusion. $A-D$, Trajectories $(A, B)$ and corresponding confinement index-versus-time plots $(C, D)$ of two mGluR5-myc-bound particles recorded in the absence $(A, C)$ or presence $(B, D)$ of $10 \mu \mathrm{M}$ DHPG. $E$, Histograms of the mean dwell times for diffusive and confined events detected on trajectories recorded in the absence ( gray bars) or presence (black bars) of DHPG. F, Histograms of the mean instantaneous diffusion coefficients for diffusive and confined events in the absence or presence of DHPG. Note that diffusion is always higher in the presence of DHPG.

encoding various GFP-tagged Homer and myc-tagged mGluR5 proteins (Homer1b or 1a-GFP and mGluR5-myc) in neurons. Because binding of Homer1b and mGlu5a occurs between the C-terminal domain of mGluR5a and the N-terminal EVH domain of Homer1b (Xiao, 1998), tags placed at the N-terminal domain of mGluR5a and C-terminal domain of Homer1b are not expected to disturb binding. Indeed, binding of the epitopetagged Homer1b to mGluR5 (Roche et al., 1999; Ango et al., 2000; Ciruela et al., 2000) and aggregation or coclustering of Homer tagged at the $\mathrm{N}$ - or C-terminal domain and mGluR (Tadokoro et al., 1999; Ciruela et al., 2000) have been shown.

Because neurons endogenously express Homer isoforms (Xiao, 1998), we also performed experiments in Ptk2 epithelial cells, which do not express detectable levels of Homer proteins, as revealed by the absence of immunocytochemical staining with a pan-Homer antibody (Fig. 3A,C, arrow, cells transfected with Homer1b-GFP; asterisk, nontransfected cells; arrowhead, neurons expressing endogenous Homer proteins revealed with a panHomer antibody). The absence of endogenous mGluR5 or Homer1b expression in these cells was confirmed by immunoblot experiments (Fig. 3E). These experiments also indicated that cultured hippocampal neurons endogenously express homer1b and very low levels of mGluR5. We studied and quantified mGluR5-myc distribution by surface staining of live transfected cells with anti-myc antibodies. We analyzed the relative receptor density by measuring the percentage of cell surface occupied by
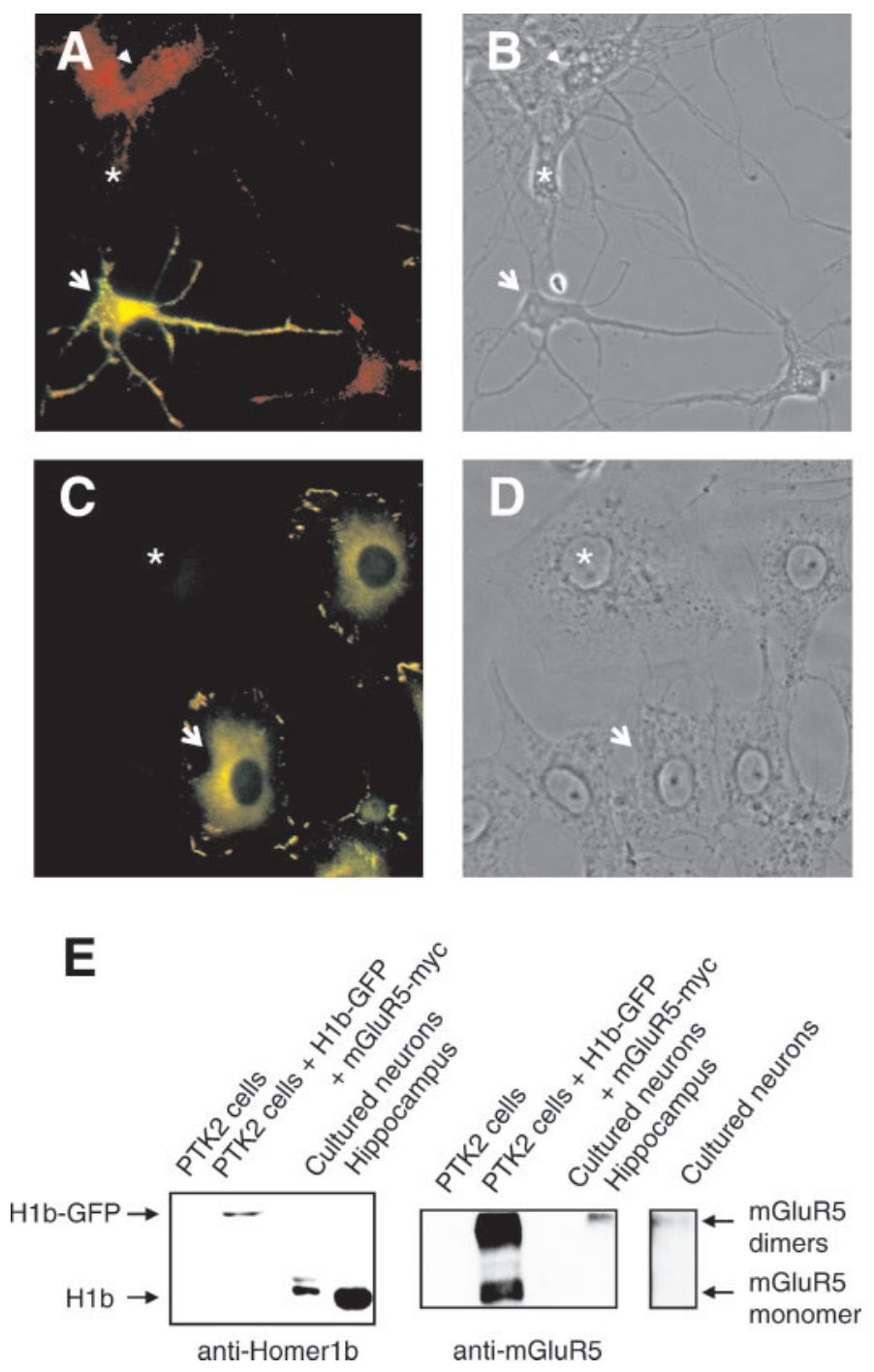

Figure 3. Comparison of endogenous and transfected levels of Homer1b and mGluR5. $A-D$, Immunocytochemical staining of endogenous Homer proteins revealed with a pan-Homer antibody $(r e d)$ in cultured hippocampal neurons $(A)$ and Ptk2 cells $(C)$ transfected or not with Homer1b-GFP (green, arrow) and phase contrast pictures of the same cells $(B, D)$. Homer1b is endogenously expressed in some cultured hippocampal neurons (red, arrowhead) but not in other neurons or nontransfected Ptk2 cells (asterisk). E, Western blots revealed by anti-Homer1b (left blot) and anti-mGluR5 (middle, right blots). Each line contained, from left to right, extracts of control Ptk2 cells, Ptk2 cells transfected with Homer1b-GFP plus mGluR5-myc, cultured hippocampal neurons, and dissected hippocampi. Arrows on the left indicate the molecular weights of 45 and 71 $\mathrm{kDa}$, corresponding, respectively, to Homer1b and Homer1b-GFP. $\mathrm{Ar}$ rows on the right indicate the molecular weights of 150 and $300 \mathrm{kDa}$ corresponding, respectively, to monomeric and dimeric mGluR5. Control Ptk2 cells express no Homer1b or mGluR5, whereas cultured neurons express Homer1b and low levels of mGluR5, as revealed on the right-most line, which is the same as that for the middle blot but exposed for a longer time.

pixels with a fluorescence level above the average cell fluorescence (these represent $\sim 50 \%$ of the immunostaining). We then defined clusters as regions where the fluorescence is twice above the average cell fluorescence.

mGluR5-myc transfected in cultured hippocampal neurons is partly concentrated in small clusters in the plasma membrane (Fig. $4 A$; mean surface of clusters \pm SEM, $0.97 \pm 0.26 \mu \mathrm{m}^{2} ; n=$ 


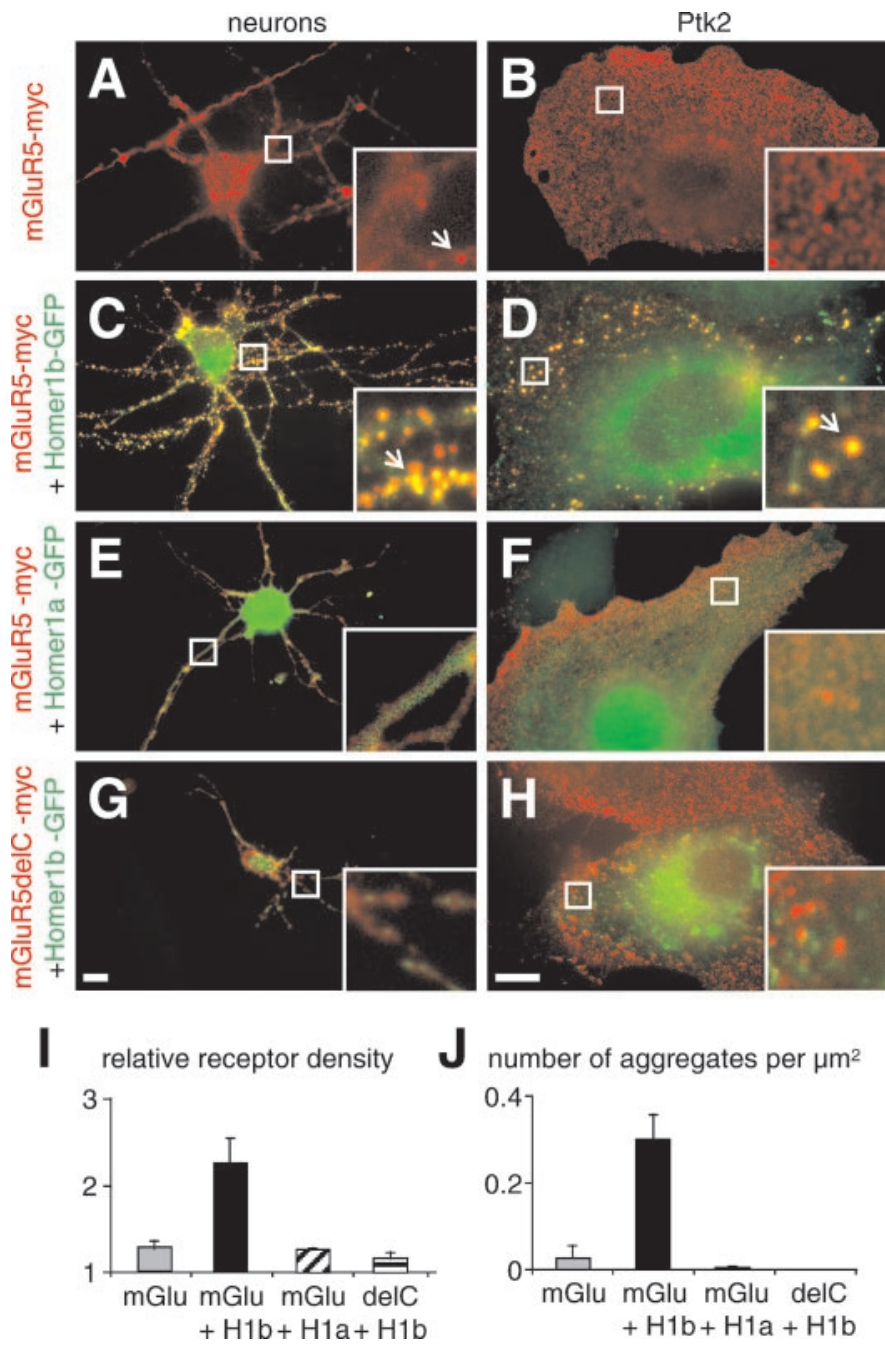

Figure 4. mGluR5 is coaggregated with Homer1b in surface clusters. Surface expression of myc-tagged mGluR5 variants $(\mathrm{red})$ in neuronal $(A$, $C, E, G)$ or Ptk2 $(B, D, F, H)$ cells cotransfected or not with GFP-tagged Homer variants ( green) is shown. Diff use distribution at the cell surface of full-length mGluR5-myc expressed alone $(A, B)$ or coexpressed with Homer1a-GFP $(E, F)$ and of mGluR5-DelC-myc coexpressed with Homer1b-GFP $(G, H)$ is shown. Only coexpression of full-length mGluR5-myc plus Homer1b-GFP promotes the formation of clusters in which both proteins colocalize $(C, D)$. Scale bar, $10 \mu \mathrm{m}$. Insets, $5 \times$ magnifications of the subregions indicated in each panel. Arrows point to examples of clustered receptors. I, Quantification of the relative density of full-length or truncated mGluR5-myc in Ptk2 cells \pm SEM, in the presence or absence of short (H1a-GFP) or long (H1b-GFP) forms of Homer. $J$, Measure of the mean number of mGluR5-myc-containing clusters \pm SEM in the same conditions.

11 cells). The amount of fluorescence in clusters accounts for $26 \pm 4.8 \%$ ( $n=11$ cells) of the total mGluR5-myc immunostaining. Homer1b transfected in Ptk2 cells and cultured hippocampal neurons displays a diff use cytosolic repartition, without obvious clustering (data not shown; Tu et al., 1999). When Homer1b-GFP is cotransfected with mGluR5-myc, both proteins are colocalized in clusters (Fig. $4 C$; mean surface of clusters, $0.92 \pm 0.14 \mu \mathrm{m}^{2}$; $n=6$ cells $)$. Clustered receptors account for $56 \pm 6.9 \%(n=6$ cells) of the mGluR5-myc immunostaining. Thus expression of Homer1b-GFP in neurons increases the percentage of mGluR5myc in clusters but not the size of clusters. In Ptk2 cells (Fig. $4 B, D)$, mGluR5-myc expressed alone lacks significant clustering, whereas coexpression of Homer1b induces colocalization of both proteins in clusters (amount of fluorescence in clusters accounts for $3 \pm 1$ and $39 \pm 3 \%$ of the total mGluR5-myc immunostaining in cells expressing mGluR5-myc alone or mGluR5-myc plus Homer1b, respectively; $n=10$ cells in each condition; mean surface of these clusters measured in the presence of Homer1b, $\left.0.29 \pm 0.03 \mu \mathrm{m}^{2}\right)$.

Thus, expression of Homer1b-GFP results in the clustering of mGluR5-myc in neurons and Ptk2 cells. Furthermore, it has been suggested that the coaggregation of mGluR5 and Homer1b requires the $\mathrm{C}$ termini of both proteins (Xiao, 1998). Indeed, coexpression of a cytoplasmic tail deletion variant of mGluR5myc (mGluR5-delC-myc) and Homer1b-GFP or coexpression of mGluR5-myc and Homer1a-GFP does not induce clustering of the receptor in both neurons and Ptk 2 cells (Fig. $4 E-H$ ). It should be noted, however, that even in the absence of an mGluR5Homer interaction, mGluR5 distribution could display some heterogeneity, but to a much lesser degree than in the presence of an interaction with Homer1b. The origin of this weak distribution heterogeneity is unknown and could represent intrinsic heterogeneity in membrane structure or weak aggregation of mGluR5 by an endogenous mGluR5-binding protein. The level of mGluR5 clustering is quantified for Ptk2 cells in Figure $4 I-J$, which shows that receptor density is close to 1 in all cases, except for the full-length receptor in the presence of Homer1b. In this case, receptors are enriched in clusters by a factor of 2.2 .

\section{Full-length Homer shifts mGluR5 movement toward confined states}

We then analyzed the influence of Homer proteins on mGluR5 movement by SPT. Periods of slow diffusion appear longer for cells coexpressing mGluR5-myc and Homer1b-GFP (Fig. 5C,D) than for cells expressing mGluR5-myc alone (Fig. 5A,B), mGluR5-myc together with Homer1a-GFP, or mGluR5-delCmyc together with Homer1b-GFP (data not shown). An averaged quantification of receptor movement was first obtained by calculating the MSD of the whole trajectories (Fig. 5E,F). Overall, for mGluR5-myc movements, the mean slope at the origin of the MSD plot is significantly smaller and the curvature is greater in the presence than in the absence of Homer1b-GFP (Fig. 5E,F). This indicates that expression of Homer1b decreases the mean diffusion rate and increases the confinement of mGluR5-myc.

We compared the dynamics of entry and exit of mGluR5-myc from confined domains with and without Homer (Fig. 6). The presence of Homer1b mainly decreased the proportion of long diff usive times and increased that of long confined times. This was most apparent on plots of the cumulative distributions of dwell times, which give the fraction (or the probability) of observations falling in or below each value (Fig. 6A,B). The distributions of diffusive and confined dwell times both follow biexponential laws. This indicates that dynamics between the diffusive and confined states follow complex kinetic schemes and suggests that multiple diffusive and confined states may exist. It is of interest to note that rate constants of exchange between these states could be derived from these dwell time distributions. The mean duration of diffusive events for mGluR5-myc is markedly reduced by the presence of Homer1b-GFP, whereas the mean duration of confined events is increased (Fig. 6C). In Ptk2 cells, the mean diffusive duration decreases from $48 \pm 8 \mathrm{sec}(n=12)$ to $30 \pm 4 \mathrm{sec}(n=13)$ on addition of Homer1b-GFP, whereas the mean confined duration increases from $20 \pm 5$ to $39 \pm 10 \mathrm{sec}$. A probability of confinement was computed for each trajectory as 


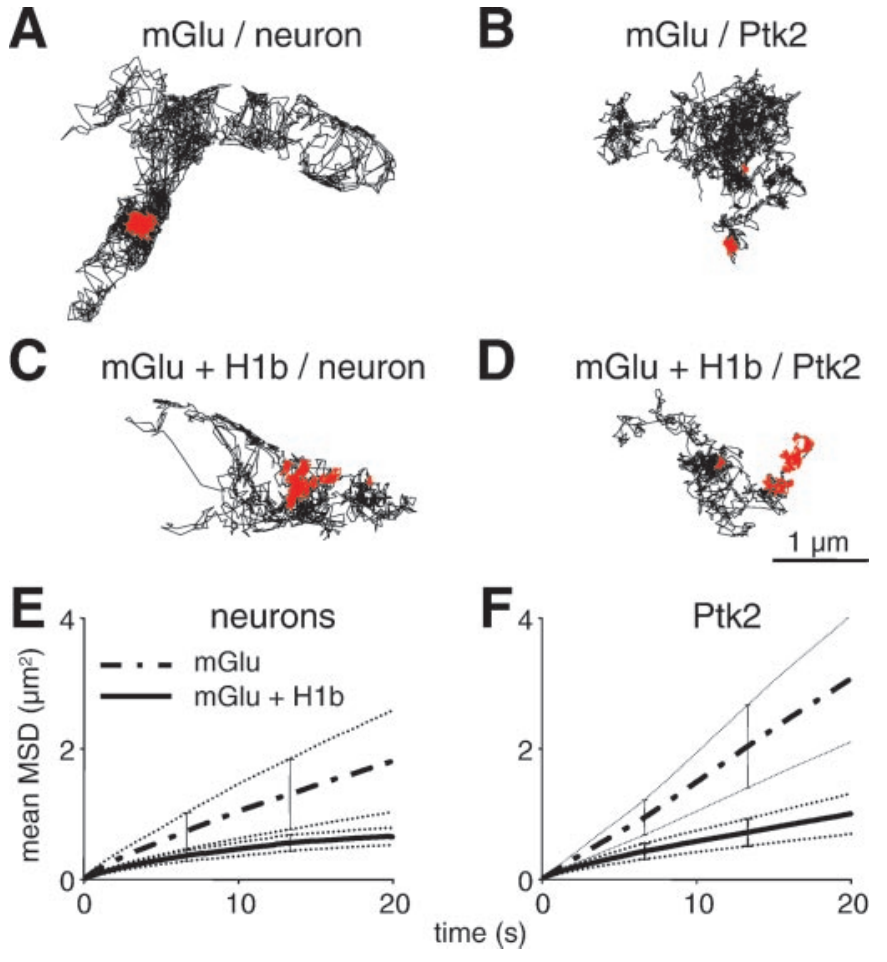

Figure 5. Movements of mGluR5-myc are more confined in the presence of Homer1b. A, F, Typical trajectories of latex beads coupled to mGluR5myc in the presence or absence of Homer proteins expressed in neurons $(A, C)$ or Ptk2 epithelial cells $(B, D)$. Bead positions are shown for $200 \mathrm{sec}$ (sampling at $25 \mathrm{~Hz}$ ). Note that in the presence of Homer1b $(C, D)$, particularly in neurons $(C)$, beads remained for long times confined in subdomains (red). Calibration is identical for all plots. $E, F$, Plots of the means of the mean square displacement-versus-time function for trajectories recorded in neurons (left) or in Ptk2 cells (right) expressing mGluR5-myc alone (dotted line) or together with Homer1b-GFP (solid line). The number of trajectories lies between 30 and 43 for each curve. Error bars indicate SEM. Note that in both cell types the slope of the MSD curve is smaller in the presence of Homer1b $(p<0.05$, Student's $t$ test on last values).

the confined time divided by the total time of the trajectory (Fig. $6 D$ ). Homer1b-GFP increases the probability for mGluR5-myc to be in a confined state both in Ptk2 cells and in neurons. Furthermore, both Homer1b-GFP and Homer1b-myc lead to a similar probability for mGluR5 to be confined in Ptk2 cells (respectively, $0.59 \pm 0.06$ and $0.66 \pm 0.05$ ). In neurons, the probability of confinement for mGluR5 remains high at all days in vitro in the presence of transfected Homer1b but increases with neuronal maturation in the absence of transfected Homer1b (Fig. 6E). This could be attributable to progressive expression of endogenous Homer.

\section{Zones of confinement are apposed to clusters of Homer and receptors}

We next investigated the relationship between domains of confinement and clusters of mGluR5-myc. For this aim, we used either Homer1b-GFP or a mGluR5-myc-GFP construct containing myc at the $\mathrm{N}$ terminus and GFP at the $\mathrm{C}$ terminus of mGluR5. We verified that mGluR5-myc-GFP also interacts with Homer1b (data not shown), as expected, because the Homer binding site on mGluR5 lies $\sim 50$ amino acids away from the $\mathrm{C}$ terminus. Because GFP fluorescence of tagged receptors does not allow discrimination of internal versus surface-expressed receptors, we first performed simultaneous visualization of total GFP fluorescence and
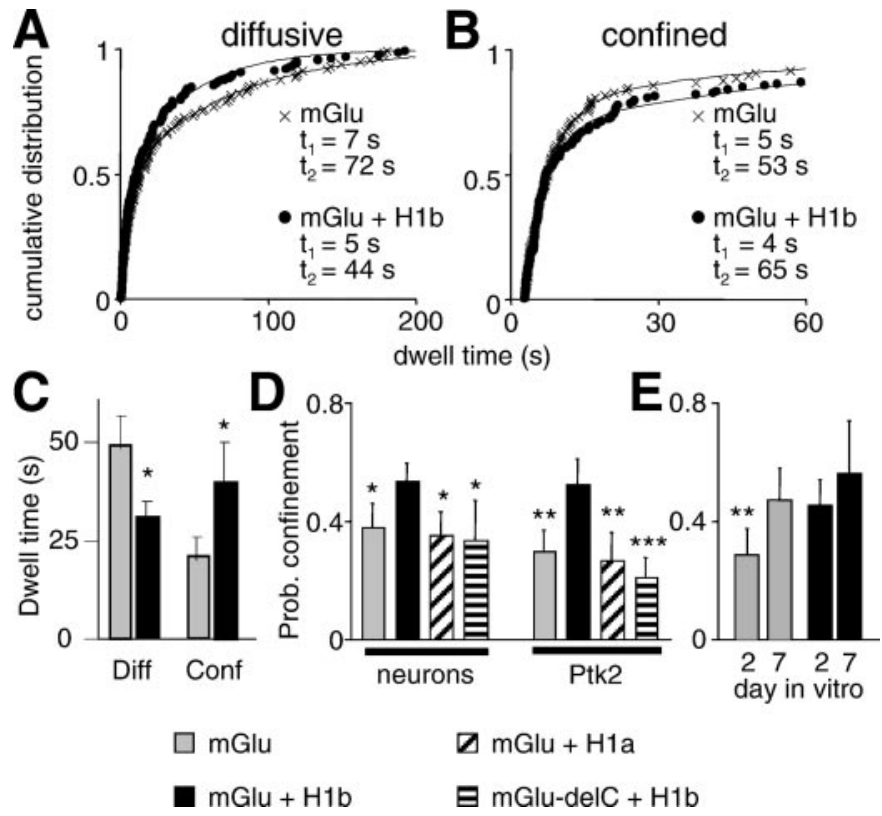

Figure 6. Kinetic properties of the equilibrium between the confined (Conf) and diffusive (Diff) states of mGluR5-myc. $A, B$, Plots of the cumulative distribution versus time of diffusive $(A)$ and confined $(B)$ dwell times in Ptk2 cells expressing mGluR5-myc alone (circles) or together with Homer1b (crosses). Curves were fitted with the sum of two exponential functions with time constants as indicated. $C$, Histograms of the mean values of the dwell times in the diffusive and confined states in Ptk2 cells expressing mGluR5 alone or mGluR5 plus Homer1b. D, E, Histograms of the mean values of the probability to be in a confined state \pm SEM in neurons pooled at all ages $(D)$ or as specified $(E)$ and in Ptk2 cells $(D)$ expressing the indicated variants of mGluR5-myc and Homer. Note that this probability is highest for full-length mGluR5-myc plus Homer1b and that this value increases with neuronal maturation for mGluR5 alone but remains high in the presence of Homer1b. Each value was compared with that in the presence of mGluR5 plus Homer1b with Student's $t$ test: ${ }^{*} p<0.05 ;{ }^{*} p<0.01 ; * * p<0.001$.

surface-expressed mGluR5-myc-GFP through surface labeling of the myc epitope on live cells. We found that in neurites, most mGluR5-myc-GFP clusters were expressed at the cell surface ( $>95 \%$ of clustered GFP fluorescent spots in neurites were costained with surface anti-myc; $n=8$ neurons; data not shown). In contrast, the cell body mainly exhibited intracellular receptors. We thus performed tracking of the movement of GFP clusters in neurites, confident that most of them reveal movement of surface clusters.

We simultaneously visualized GFP by epifluorescence and the movement of the mGluR5-myc- or mGluR5-myc-GFP-bound latex beads on transfected live neurons. In the case of experiments with mGluR5-myc-GFP, we used a nonfluorescent form of Homer1b. Our data indicate that in experiments with GFP tags on Homer or mGluR5, zones of confinement were often close or on top of clusters of Homer1b-GFP or mGluR5-GFP, respectively (Fig. 7). This was quantified by measuring for each trajectory the distance between confinement zones and the nearest GFP cluster and comparing this value with the mean intercluster distance. We found that 71 and $63 \%$ of the zones of confinement were at $<0.5 \mu \mathrm{m}$ from a Homer1b-GFP and a mGluR5-myc-GFP cluster, respectively. This value was chosen as a threshold because it corresponds to the diameter of the bead. In contrast, the mean intercluster distance was $2.55 \pm 0.61$ and $0.95 \pm 0.43 \mu \mathrm{m}(n=14$ and 11 beads on five and eight cells, respectively) for Homer1b- 
A

Homer1b-GFP
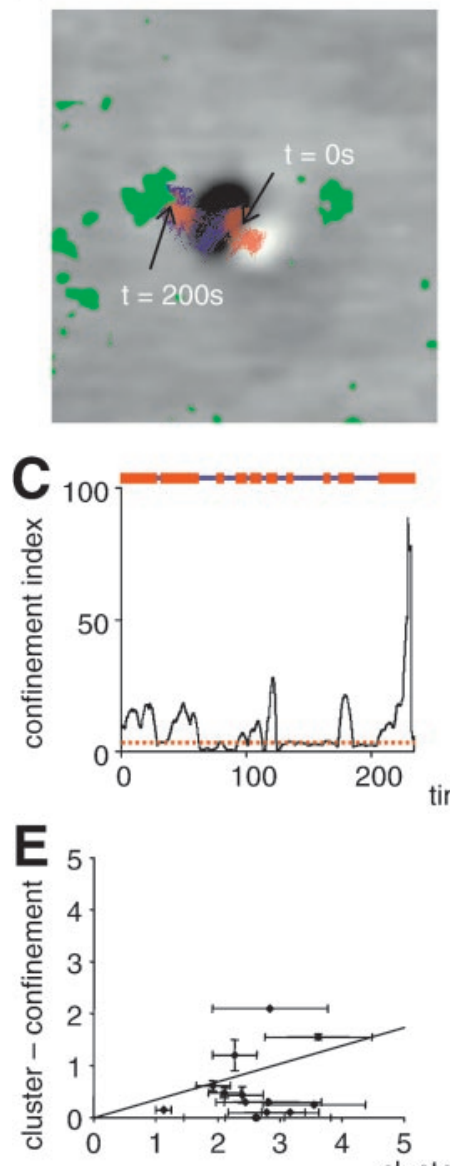

B
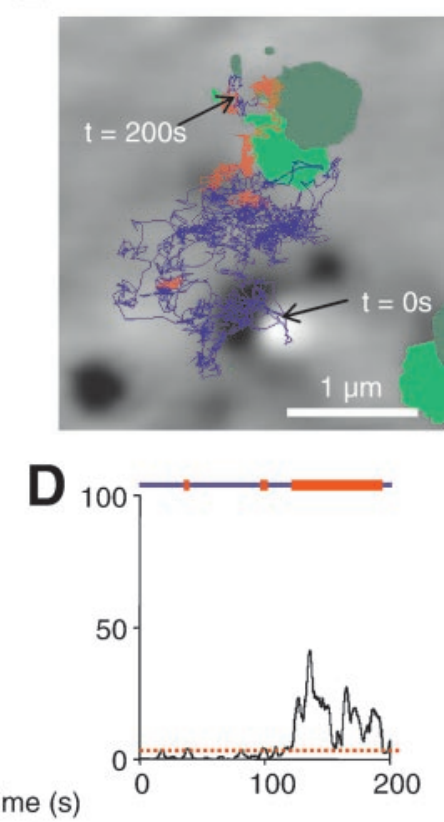

$\mathbf{F}_{5}$

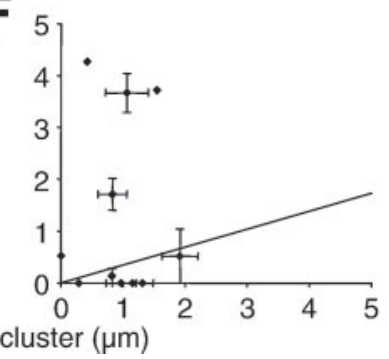

Figure 7. Receptors in a confined state are associated with Homer and mGluR5 clusters. $A, B$, Simultaneous visualization of mGluR5-myc trajectories and fluorescence of Homer1b-GFP $(A)$ or mGluR5-myc-GFP $(B)$ in two hippocampal neurons cotransfected with mGluR5-myc and Homer1b-GFP $(A)$ or mGluR5-myc-GFP and Homer1b-myc $(B)$. The initial $\left(t_{\mathrm{i}}=0 \mathrm{sec}\right)$ and final $\left(t_{\mathrm{f}}=200 \mathrm{sec}\right)$ positions of the receptors are indicated by arrows. The differential interference contrast image (gray level) of the cells is combined with the binarized fluorescence image of GFP. In $B$, the GFP cluster moved in parallel with the confined trajectory, and its initial and final positions are represented in dark and light green, respectively. $C, D$, Corresponding plot of confinement index versus time for the trajectories represented in $A$ and $B$, respectively. Note that beads can bind and unbind repetitively from the same cluster $(A, C)$ or follow cluster movements $(B) . E, F$, Plots of the mean distance between confinement domain and nearest GFP cluster versus mean intercluster distance for experiments as in $A$ and $B$, respectively. Each point corresponds to the mean measures on one trajectory. The line draws the border below which the distance between confinement periods and nearest GFP cluster is below that expected for a random distribution.

GFP and mGluR5-myc-GFP clusters, respectively. This indicates that confinement domains displayed by mGluR5-bound latex beads can be specifically spatially associated with clusters. This set of experiments also permitted direct visualization of mGluR5 binding and unbinding to and from the periphery of a cluster (Fig. $7 A$ ). Furthermore, the slow movement of receptors during confinement could be matched to cluster drift on some occasions (Fig. 7B). Altogether, these data indicate that part of the transitions between freely diffusive and confined behavior of mGluR5 reflects reversible interactions with clusters of receptors containing Homer1b. They further suggests that slow diffusion of recep-

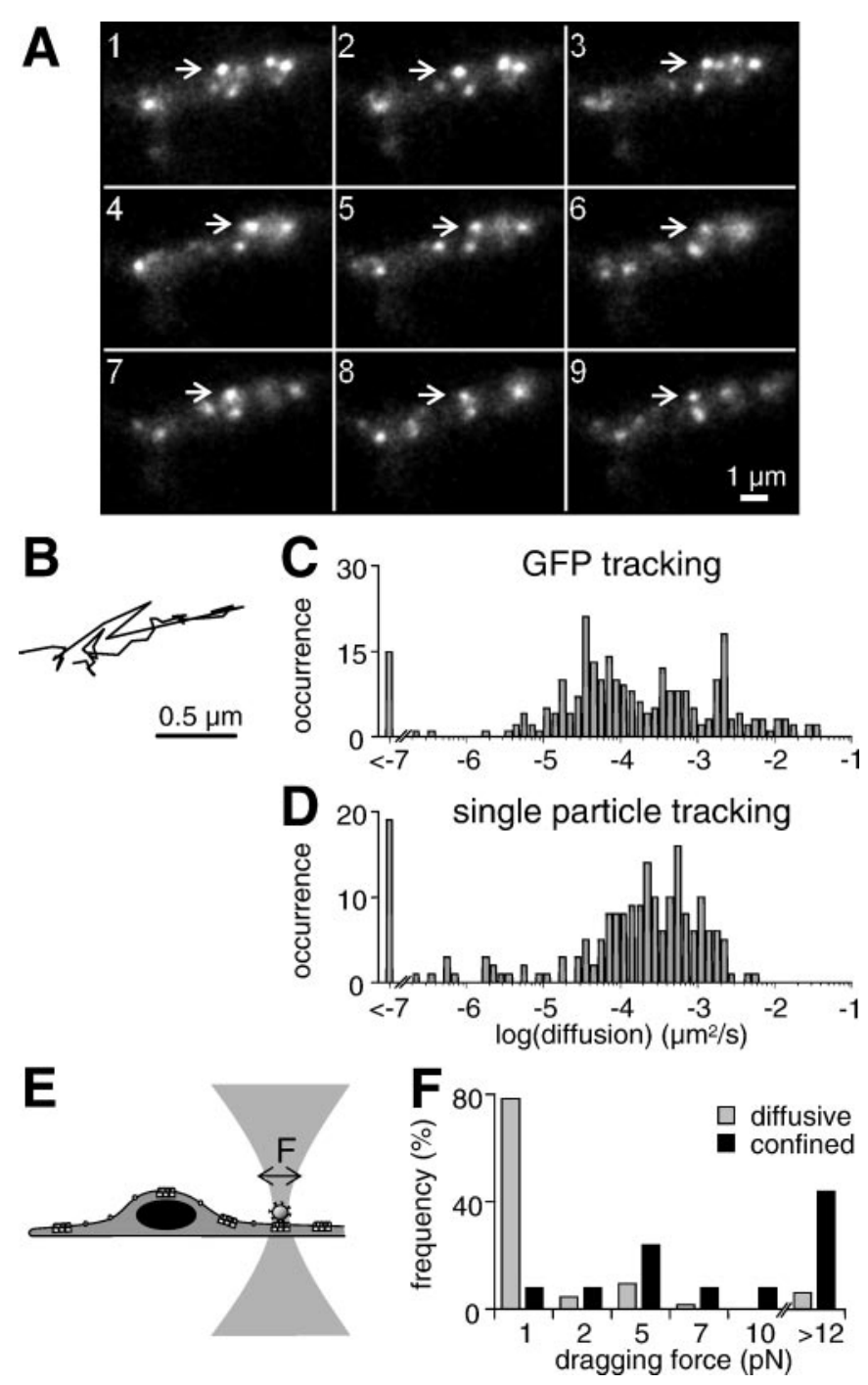

Figure 8. mGluR5-GFP clusters diffuse in the plasma membrane. $A$, Time-lapse images of epifluorescence of a neuron cotransfected with mGluR5-GFP and Homer1b. Sample time, $25 \mathrm{sec}$. The movement of a diffusing cluster is highlighted by the arrows, with the corresponding trajectory in $B$. C, Plot of the distribution of the cluster diffusion coefficients computed from tracks of images as in $A . D$, Plot of the distribution of the asymptotic diffusion coefficients measured on MSD plots during confined events in SPT experiments performed on neurons coexpressing mGluR5-myc and Homer1b. E, F, Analysis of the minimum force required to drag receptors in the plane of the membrane in the confined and diffusive states. Note that diff usive receptors require a minimal force to be dragged, whereas confined receptors can be either immobilized or dragged by an intermediate force.

tors during confined periods probably reflects global movement of clusters rather than diffusion of receptor within the cluster itself.

\section{Clustered receptors display two levels of lateral mobility}

We further analyzed the movement of mGluR5 clusters in neurons through time-lapse recordings of mGluR5-myc-GFP fluorescence. We performed tracking of the movement of GFP clusters in neurites, where most of them reveal movement of surface clusters (Fig. 8A). These experiments revealed that clusters fell in two categories exhibiting fast and slow diffusion coefficients, ranging from $10^{-7} \mu \mathrm{m}^{2} / \mathrm{sec}$ for the most immobile clusters up to $5 \times 10^{-2} \mu \mathrm{m}^{2} / \mathrm{sec}$ for the fastest clusters. Interestingly, these 
values span a similar range as that of the values of the asymptotic diffusion coefficients measured on confined events with SPT.

The heterogeneity in cluster movement could arise from differential binding to rigid structures such as cytoskeletal elements. To test this hypothesis directly, we returned to SPT and measured the force necessary to drag the receptors in the plane of the membrane with laser tweezers during the different stages of movement in cells coexpressing mGluR5-myc and Homer1b-GFP (Fig. 8E,F). During periods of free diffusion, receptors could be dragged freely over large distances by applying a $1 \mathrm{pN}$ dragging force on the bead in $78 \%$ of the trials $(n=64)$. In contrast, during periods of reduced diffusion, a large fraction $(44 \% ; n=25)$ of receptors could not be dragged, even with forces of $>12 \mathrm{pN}$. This indicates that these receptors are bound to a rigid structure. Interestingly, there remained a population of receptors that could be dragged by intermediate forces $(F=5.1 \pm 0.77 \mathrm{pN} ; n=14)$, although their lateral diffusion coefficient was low. These data indicate that receptors in a confined state can be either anchored or not to a rigid structure. These two states could correspond to the two different states of mobility visualized through fluorescence tracking of mGluR5-myc-GFP.

\section{Fast reversibility of receptor clustering is confirmed by FRAP}

So far, our SPT experiments strongly suggest that receptors can go in and out of clusters. To circumvent possible artifacts caused by the presence of the bead, we decided to test this hypothesis further using a totally different approach. The principle of FRAP is to photobleach a small area and measure its fluorescence continuously. The speed of return of fluorescence in the bleached area is a direct estimate of the diff usion coefficient of diff usive receptors, whereas the fraction of recovery is an indication of the fraction of mobile receptors. FRAP was performed on neurons cotransfected with mGluR5-GFP and Homer1b. We selected two types of regions, containing predominantly either scattered or clustered receptors. Fluorescence recovery was slower when the receptors contained in the measured region were clustered than when they were scattered (Fig. 9; $p<0.001$ ). These slower recovery times translate into lower diffusion coefficients for receptors in clusters $\left(D=0.04 \pm 0.01 \mu^{2} / \mathrm{sec}\right)$ than for those scattered $\left(D=0.11 \pm 0.02 \mu \mathrm{m}^{2} / \mathrm{sec}\right)$. Most interestingly, the fraction of recovery was on the order of $50 \%$ for both types of regions, indicating that the bleached clustered receptors could be replaced within tens of seconds by unbleached ones. Derivation of diffusion coefficients from FRAP and particle-tracking experiments led to comparable results for diff usive receptors (0.09 and $0.11 \mu \mathrm{m}^{2} / \mathrm{sec}$, respectively). Data from clustered receptors cannot be compared directly, because FRAP measures reentry of receptors in clusters, whereas particle tracking measures diffusion of the cluster. Incomplete recovery at this time scale could be attributable to spatial limits within which receptors can diffuse, thus limiting the pool of receptors available around the bleached spot for repopulation. It could also arise from a less mobile population of receptors that is replaced more slowly, for example, within the center of the cluster, or both.

\section{DISCUSSION}

mGluR5-myc alternates between periods of fast and slow diffusion. Activation of mGluR5 increases overall receptor diffusion without affecting the balance between its different mobility states, whereas the mGluR5-interacting protein Homer increases the residency time in the slow diffusion state. Combination of fluo-
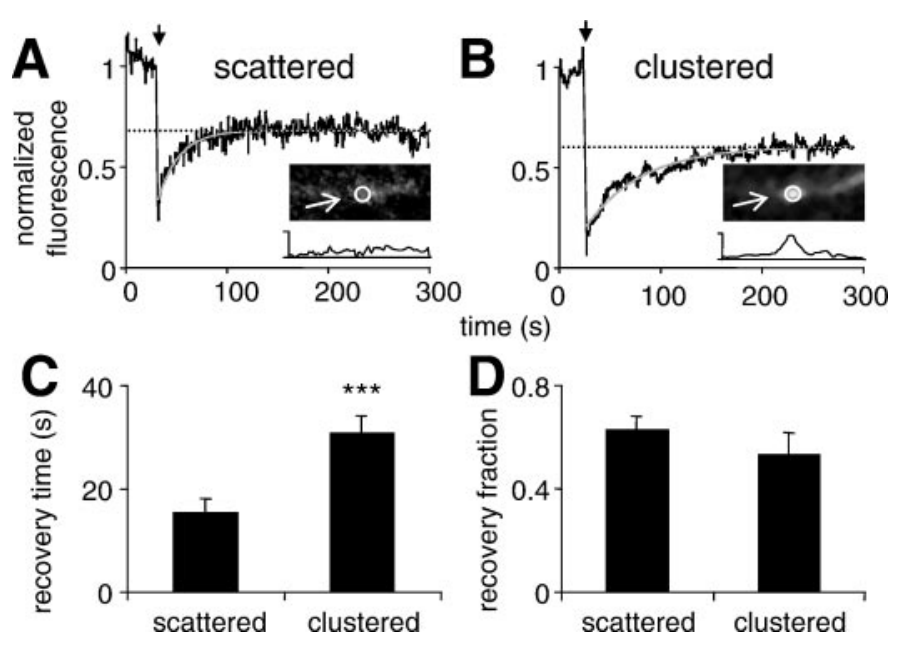

Figure 9. Reversibility of cluster composition visualized by FRAP. $A, B$, Plots of the normalized fluorescence intensity of mGluR5-GFP versus time before and after photobleaching (vertical arrow), recorded in a region containing scattered $(A)$ or clustered $(B)$ receptors. The fluorescence intensity is monitored on neurons cotransfected with mGluR5-GFP and Homer1b on a 2.1- $\mu \mathrm{m}$-diameter region, as depicted by the white arrow in the inset. Spots of clustered receptors are identified as peaks on line scans of fluorescence intensity (insets). The recoveries are fitted with single exponentials to measure the half-recovery times, as indicated. $C$, Histogram of mean half-recovery times for regions containing scattered or clustered receptors. Note that recovery is slower for clusters. $D$, Histogram of mean recovery fractions for regions containing scattered or clustered receptors. Note that clusters recover to the same extent as scattered receptors. ${ }^{* * *} p<0.001$.

rescence imaging of mGluR5-GFP or Homer with SPT indicates that confined states correspond most to receptors being associated with mGluR5-Homer clusters. Taken together, FRAP and SPT experiments show that the composition of receptor clusters is in continuous renewal.

\section{Physiological regulation of mGluR5 states of mobility}

mGluR5 alternated between states of different mobility. Receptors in a state of free Brownian diffusion displayed a low confinement index and a linear MSD function and could be dragged by forces of $<1 \mathrm{pN}$ for distances over several micrometers. This agrees with the notion that during free diffusion, receptor movement is only limited by viscous forces. It indicates that diffusive movements of mGluR5 during these periods are not restricted by membrane fences (Kusumi et al., 1993; Simson et al., 1998). During periods of reduced diffusion detected by a high confinement index, the MSD function was negatively curved, independently confirming that diffusion was restricted ("confined") to submembranous areas.

Two physiological processes regulate mGluR5 mobility. First, activation of the receptor with the group I mGluR agonist DHPG tripled the diff usion coefficient in the mobile and confined states. In contrast, the time spent in each state did not vary. It is thus unlikely that mGluR activation regulates specific interaction with stabilizing intracellular partners. Rather, activation-induced uncoupling of $\mathrm{G}_{\mathrm{q}}$ from mGluR5 (De Blasi et al., 2001) could promote lateral mobility of mGluR5 by alleviating steric hindrance during passive interactions with submembranous material such as cytoskeletal elements (Simson et al., 1998).

Second, interaction of mGluR5 with Homer modifies the equilibrium between states toward a higher residency time in the confined state. The mGluR5-Homer1b interaction at the cell 
surface was visualized both by the appearance of clusters of mGluR5 in which Homer1b and mGluR5 colocalized and by a $30 \%$ (in neurons) to $70 \%$ (in Ptk2 cells) increase in the percentage of time spent by mGluR5 in the confined state. Interestingly, in the presence of Homer1b, mGluR5 still alternated frequently between periods of confinement and free diff usion. A large proportion of the confined periods likely correspond to receptors physically associated with clusters of Homer1b-mGluR5. The diffusive periods would correspond to receptors scattered in the membrane. An intriguing question is the nature of the confined state in the absence of transfected Homer1b. In neurons, periods of reduced diffusion could be attributable to interaction with endogenous Homer. They were, however, still observed with Homer1a, which is supposed to compete for full-length HomermGluR5 interaction, and when the Homer interaction site was deleted in mGluR5. In Ptk2 cells, where Homer is undetectable, mGluR5, as its tail-minus mutant, still displayed confined episodes for $25-30 \%$ of the total time. Thus, this fraction of periods of confinement independent of Homer may correspond to lowaffinity binding of mGluR5 to an unidentified molecule or to nonspecific corralling of receptor movement by membrane subdomains or cytoskeleton fences (Sako and Kusumi, 1994).

\section{Dynamics of clustered receptors}

Several arguments support the notion that clusters of receptors have a dynamic composition on the time scale of seconds, although their apparent size appears constant. First, in SPT experiments, we visualized receptors exchanging between adjacent clusters and repetitive binding and unbinding from the periphery of a cluster. Second, FRAP experiments demonstrated that fluorescence of bleached mGluR5 clusters recovered within tens of seconds, showing that receptors repopulate these clusters rapidly.

Large variability was observed in the mobility and resistance to dragging of clusters as a whole by converging fluorescence, SPT, and force measurements. This suggests that they have different states of binding to rigid structures. They may float freely in the membrane, displaying diffusion rates reaching nearly that of scattered receptors, as predicted by the theory of Saffman (1976). Clusters may also be immobilized through binding to rigid structures. mGluR5 might be bound to actin through the N-terminal domain of Homer1b (Shiraishi et al., 1999) or directly to microtubules as for mGluR1 (Ciruela et al., 1999).

Movement of receptors during confined events is restricted either by obstacles or within a membrane subdomain (Kusumi et al., 1993; Simson et al., 1998). Within the latter hypothesis, the slope of the asymptote gives the lateral diffusion rate of the subdomain, whereas the instantaneous diff usion coefficient (slope of the MSD at the origin) gives the diffusion rate of the receptor within the subdomain. Two sets of data support our hypothesis that the asymptotic diffusion coefficient measured on the MSD plots corresponds to the lateral diffusion of clusters. First, on occasions, we could correlate drift of Homer1b-GFP clusters and movement of confinement domains. Second, we observed that the range of asymptotic diffusion rates matches that measured by fluorescence of mGluR5-GFP clusters. The instantaneous diffusion could correspond to diffusion of receptors within the cluster or to a rotational diffusion of the clustered receptors. Indeed, some confined parts of trajectories clearly depict rotational diffusion (data not shown), as would be expected for a particle situated at the boundary of a semirigid disk diffusing in the membrane. Altogether, we propose that the movement of scattered receptors is Brownian, whereas clustered receptors move as a semirigid disk floating in the membrane. This movement is the sum of rotational and translational diffusion.

\section{Role of receptor dynamics in physiology}

Similar dynamic properties and regulation by Homer were observed in Ptk 2 cells and in neurons cultured for $2 \mathrm{~d}$. In both cases, there are no synapses; therefore antibody-coated beads have access to all surface receptors. In neurons cultured for $7 \mathrm{~d}$, synaptogenesis has started, but we observed similar behavior of mGluR5. Our measurements thus probably provide good estimates of the parameters of extrasynaptic receptor movements. In the absence of direct measurements, we do not know what is the actual residency time, i.e., affinity, of mGluR5 at synaptic sites. Furthermore, we have not been able to perform experiments in older, more mature neurons, which may display different membrane properties. However, we show that, if freed from the synapse, receptors will diffuse rapidly in the extrasynaptic membrane until they find another binding site.

In our cotransfection experiments, we have formed domains enriched in mGluR5, which resembles the situation of the postsynaptic membrane. That receptors are not irreversibly trapped in these domains but can escape from them by lateral diffusion is of importance to understand how receptor clusters are formed and modified in plastic processes. Although mGluR5 is enriched at postsynaptic sites to an annulus surrounding the PSD (Baude et al., 1993; Nusser et al., 1994), up to $75 \%$ of the receptors can be found at nonsynaptic sites (Lujan et al., 1997). This distribution can be interpreted as mGluR5 being in a dynamic equilibrium between a freely diffusive state outside the synapse and an immobilized state at synaptic sites, bound to Homer or other scaffold proteins. Recent results indicated that the synaptic localization of Homer is regulated within minutes by calcium influx through NMDA receptors (Okabe et al., 2001). This can potentially modify the residence time, and thus the number, of mGluR5 at synapses.

That clusters are relatively mobile is relevant to addressing receptors to synaptic sites. Receptors can be addressed and inserted in the membrane at sites remote from the cell body after intracellular trafficking along neurites (for review, see Craig and Boudin, 2001). Alternatively, receptors could be inserted in the somatic membrane and then diffuse laterally in the plasma membrane of neurites until trapped at remote synaptic sites by interaction with scaffolding proteins. Such a diffusion-trap mechanism, proposed for the building of $\mathrm{ACh}$ receptors at the neuromuscular junction (Young and Poo, 1983; Akaaboune et al., 1999), was also shown at central inhibitory (Rosenberg et al., 2001) and excitatory (Passafaro et al., 2001) synapses. Thus mGluR5 could be trafficked far away in neurites through lateral diffusion, even when it is clustered with Homer.

We recently showed that glycine receptors (GlyRs) are reversibly stabilized by the scaffolding protein gephyrin (Meier et al., 2001). The diffusion of mGluR5 in both the scattered and clustered states is approximately five times faster than that of GlyRs in the corresponding states. By contrast, mGluR5 spends more time in the confined state in the presence of Homer1b than does GlyR in the presence of gephyrin. Thus, rates of diff usion and probability of confinement are not directly related. Despite these quantitative differences, we propose as a general rule that receptor-scaffold protein interactions are reversible on a short time scale, and this property is relevant to the plasticity of the composition of the postsynaptic density. The number of receptors present in the postsynaptic density at a given time will be directly 
related to the residence time of the receptors at that location. Although few extrasynaptic receptors may exist at a given time point, any receptor may enter a diffusive state within a short period and thus travel long distances. This allows receptors to exchange rapidly between regional specializations such as synapses and to enter processes likely to occur only outside the synapse. Receptors freed from synaptic confinement might therefore (1) be exchanged between synapses, thus changing the number of receptors in a synaptic cluster, and (2) diff use away from postsynaptic densities to enter the endocytotic pathway, thus contributing to turnover. Changes in either the number of stabilizing molecules or their affinity for receptors would regulate these transitions. Such mechanisms can operate in synaptogenesis and synaptic plasticity.

\section{REFERENCES}

Akaaboune M, Culican SM, Turney SG, Lichtman JW (1999) Rapid and reversible effects of activity on acetylcholine receptor density at the neuromuscular junction in vivo. Science 286:503-507.

Ango F, Pin JP, Tu JC, Xiao B, Worley PF, Bockaert J, Fagni L (2000) Dendritic and axonal targeting of type 5 metabotropic glutamate receptor is regulated by homer1 proteins and neuronal excitation. J Neurosci 20:8710-8716.

Ango F, Prezeau L, Muller T, Tu JC, Xiao B, Worley PF, Pin JP, Bockaert J, Fagni L (2001) Agonist-independent activation of metabotropic glutamate receptors by the intracellular protein Homer. Nature 411:962-965.

Axelrod D, Koppel DE, Schlessinger J, Elson E, Webb WW (1976) Mobility measurement by analysis of fluorescence photobleaching recovery kinetics. Biophys J 16:1055-1069.

Baude A, Nusser Z, Roberts JDB, Mulvihill E, McIhinney RAJ, Somogyi $\mathrm{P}$ (1993) The metabotropic glutamate receptors (mGluR1 $\alpha$ ) is concentrated at perisynaptic membrane of neuronal subpopulations as detected by immunogold reaction. Neuron 11:771-787.

Brakeman PR, Lanahan AA, O'Brien R, Roche K, Barnes CA, Huganir RL, Worley PF (1997) Homer: a protein that selectively binds metabotropic glutamate receptors. Nature 386:284-288.

Carroll RC, Beattie EC, von Zastrow M, Malenka RC (2001) Role of AMPA receptor endocytosis in synaptic plasticity. Nat Rev Neurosci 2:315-324.

Choquet D, Felsenfeld DP, Sheetz MP (1997) Extracellular matrix rigidity causes strengthening of integrin-cytoskeleton linkages. Cell 88:39-48.

Ciruela F, Robbins MJ, Willis AC, McIlhinney RA (1999) Interactions of the C terminus of metabotropic glutamate receptor type 1alpha with rat brain proteins: evidence for a direct interaction with tubulin. J Neurochem 72:346-354.

Ciruela F, Soloviev MM, Chan WY, McIlhinney RA (2000) Homer-1c/ Vesl-1L modulates the cell surface targeting of metabotropic glutamate receptor type 1alpha: evidence for an anchoring function. Mol Cell Neurosci 15:36-50.

Craig AM, Boudin H (2001) Molecular heterogeneity of central synapses: afferent and target regulation. Nat Neurosci 4:569-578.

De Blasi A, Conn PJ, Pin J, Nicoletti F (2001) Molecular determinants of metabotropic glutamate receptor signaling. Trends Pharmacol Sci 22:114-120.

Hemar A, Olivo JC, Williamson E, Saffrich R, Dotti CG (1997) Dendroaxonal transcytosis of transferrin in cultured hippocampal and sympathetic neurons. J Neurosci 17:9026-9034.

Joly C, Gomeza J, Brabet I, Curry K, Bockaert J, Pin J-P (1995) Molecular, functional, and pharmacological characterization of the metabotropic glutamate receptor type 5 splice variants: comparison with mGluR1. J Neurosci 15:3970-3981.

Kucik DF, Elson EL, Sheetz MP (1999) Weak dependence of mobility of membrane protein aggregates on aggregate size supports a viscous model of retardation of diffusion. Biophys J 76:314-322.

Kusumi A, Sako Y, Yamamoto M (1993) Confined lateral diffusion of membrane receptors as studied by single particle tracking (nanovid microscopy). Effects of calcium-induced differentiation in cultured epithelial cells. Biophys J 65:2021-2040.

Lujan R, Roberts JD, Shigemoto R, Ohishi H, Somogyi P. (1997) Differential plasma membrane distribution of metabotropic glutamate receptors mGluR1 alpha, mGluR2 and mGluR5, relative to neurotransmitter release sites. J Chem Neuroanat 13:219-241.

Mary S, Gomeza J, Prezeau L, Bockaert J, Pin JP (1998) A cluster of basic residues in the carboxyl-terminal tail of the short metabotropic glutamate receptor 1 variants impairs their coupling to phospholipase C. J Biol Chem 273:425-432.

Meier J, Vannier C, Serge A, Triller A, Choquet D (2001) Fast and reversible trapping of surface glycine receptors by gephyrin. Nat Neurosci 4:253-260.

Naisbitt S, Kim E, Tu JC, Xiao B, Sala C, Valtschanoff J, Weinberg RJ, Worley PF, Sheng M (1999) Shank, a novel family of postsynaptic density proteins that binds to the NMDA receptor/PSD-95/GKAP complex and cortactin. Neuron 23:569-582.

Nusser Z, Mulvihill E, Streit P, Somogyi P (1994) Subsynaptic segregation of metabotropic and ionotropic glutamate receptors as revealed by immunogold localization. Neuroscience 61:421-427.

Okabe S, Urushido T, Konno D, Okado H, Sobue K (2001) Rapid redistribution of the postsynaptic density protein PSD-Zip45 (Homer 1c) and its differential regulation by NMDA receptors and calcium channels. J Neurosci 21:9561-9571.

Passafaro M, Piech V, Sheng M (2001) Subunit-specific temporal and spatial patterns of AMPA receptor exocytosis in hippocampal neurons. Nat Neurosci 4:917-926.

Roche KW, Tu JC, Petralia RS, Xiao B, Wenthold RJ, Worley PF (1999) Homer $1 \mathrm{~b}$ regulates the trafficking of group I metabotropic glutamate receptors. J Biol Chem 274:25953-25957.

Rosenberg M, Meier J, Triller A, Vannier C (2001) Dynamics of glycine receptor insertion in the neuronal plasma membrane. J Neurosci 21:5036-5044.

Saffman PG (1976) Brownian motion in thin sheets of viscous fluid. J Fluid Mech 73:593-602.

Sako Y, Kusumi A (1994) Compartmentalized structure of the plasma membrane for receptor movements as revealed by a nanometer-level motion analysis. J Cell Biol 125:1251-1264

Sako Y, Kusumi A (1995) Barriers for lateral diffusion of transferrin receptor in the plasma membrane as characterized by receptor dragging by laser tweezers: fence versus tether. J Cell Biol 129:1559-1574

Salpeter MM, Loring RH (1985) Nicotinic acetylcholine receptors in vertebrate muscle: properties, distribution and neural control. Prog Neurobiol 25:297-325.

Saxton MJ (1995) Single-particle tracking: effects of corrals. Biophys J 69:389-398

Saxton MJ, Jacobson K (1997) Single-particle tracking: applications to membrane dynamics. Annu Rev Biophys Biomol Struct 26:373-399.

Scannevin RH, Huganir RL (2000) Postsynaptic organization and regulation of excitatory synapses. Nat Rev Neurosci 1:133-141.

Shiraishi Y, Mizutani A, Bito H, Fujisawa K, Narumiya S, Mikoshiba K, Furuichi T (1999) Cupidin, an isoform of Homer/Vesl, interacts with the actin cytoskeleton and activated rho family small GTPases and is expressed in developing mouse cerebellar granule cells. J Neurosci 19:8389-8400

Simson R, Sheets ED, Jacobson K (1995) Detection of temporary lateral confinement of membrane proteins using single-particle tracking analysis. Biophys J 69:989-993

Simson R, Yang B, Moore SE, Doherty P, Walsh FS, Jacobson KA (1998) Structural mosaicism on the submicron scale in the plasma membrane. Biophys J 74:297-308.

Sun J, Tadokoro S, Imanaka T, Murakami SD, Nakamura M, Kashiwada K, Ko J, Nishida W, Sobue K (1998) Isolation of PSD-Zip45, a novel Homer/vesl family protein containing leucine zipper motifs, from rat brain. FEBS Lett 437:304-308.

Tadokoro S, Tachibana T, Imanaka T, Nishida W, Sobue K (1999) Involvement of unique leucine-zipper motif of PSD-Zip45 (Homer $1 \mathrm{c} /$ vesl-1L) in group 1 metabotropic glutamate receptor clustering. Proc Natl Acad Sci USA 96:13801-13806.

Tu JC (1998) Homer binds a novel proline-rich motif and links group 1 metabotropic glutamate receptors with IP3 receptors. Neuron 21:717-726.

Tu JC, Xiao B, Naisbitt S, Yuan JP, Petralia RS, Brakeman P, Doan A, Aakalu VK, Lanahan AA, Sheng M, Worley PF (1999) Coupling of mGluR/Homer and PSD-95 complexes by the Shank family of postsynaptic density proteins. Neuron 23:583-592.

Vidnyánszky Z, Hámori J, Négyessy L, Rüegg D, Knöpfel T, Kuhn R, Görcs T (1994) Cellular and subcellular localization of the mGluR5 metabotropic glutamate receptor in rat spinal cord. NeuroReport 6:209-213.

Xiao B (1998) Homer regulates the association of group 1 metabotropic glutamate receptors with multivalent complexes of Homer-related, synaptic proteins. Neuron 21:707-716.

Young SH, Poo MM (1983) Rapid lateral diffusion of extrajunctional acetylcholine receptors in the developing muscle membrane of Xenopus tadpole. J Neurosci 3:225-231. 